\title{
Production of bioactive Hepcidin by recombinant DNA tagging with an elastin-like recombinamer
}

A da $\operatorname{Costa}^{1 *}$, A M Pereira ${ }^{1}$, A C Gomes ${ }^{1}, \mathrm{~J} \mathrm{C} \mathrm{Rodriguez-Cabello}^{2,3}, \mathrm{M} \mathrm{Casal}^{1} \#, \mathrm{R}$

Machado $^{1 * \#}$

${ }^{1}$ CBMA (Centre of Molecular and Environmental Biology), Department of Biology,

University of Minho, Campus de Gualtar, 4710-057 Braga, Portugal

${ }^{2}$ Bioforge (Group for Advanced Materials and Nanobiotechnology), Edificio LUCIA,

Universidad de Valladolid, Valladolid, Spain

${ }^{3}$ Networking Research Centre on Bioengineering, Biomaterials and Nanomedicine

(CIBER-BBN), E-47011 Valladolid, Spain

\# - Both authors contributed equally and are listed in alphabetical order

\section{* Corresponding authors:}

Raul Machado

e-mail: raulmachado@bio.uminho.pt; raulmachado@gmail.com

\section{André Costa}

e-mail: andrecosta@bio.uminho.pt

"This is a pre-print of an article published in New Biotechnology. The final authenticated version is available online at: https://doi.org/10.1016/j.nbt.2018.07.001 ".

"Esta es una preimpresión de un artículo publicado en New Biotechnology. La versión final autenticada está disponible en línea en: https://doi.org/10.1016/j.nbt.2018.07.001 ". 


\begin{abstract}
With the lack of new chemical antibiotics and the increasing pathogen resistance to those available, new alternatives are being explored. Antimicrobial peptides (AMPs) with a broad range of effects such as antibacterial, antifungal, and antiviral, arise as one of the options. These can be produced by recombinant DNA technology however, the chromatographic methods used for peptide purification are costly and time consuming. Here, we describe the design, production, purification and assessment of the antibacterial activity of the human peptide Hepcidin, using an elastin-like recombinamer as fusion partner. The recombinant protein Hep-A200 was produced in Escherichia coli and purified by a non-chromatographic procedure, exploiting the thermal properties of A200 elastin-like recombinamer. The recombinant polymer Hep-A200 retained antibacterial activity against Gram-positive and Gram-negative species.
\end{abstract}

Keywords: antimicrobial peptide, elastin-like recombinamer, Hepcidin, antimicrobial activity. 


\section{Introduction}

Antimicrobial peptides (AMPs) are of great interest as alternatives to chemical antibiotics. These small, ribosomally synthesized peptides are part of the innate immunity of several organisms and display a plethora of different activities such as antibacterial, antifungal, antiviral, antiparasitic and even antitumor [1,2]. Additionally, AMPs also play essential roles in the immunity regulation of higher organisms such as in chemotaxis, wound healing, pro- and/or anti-inflammatory processes, or as antioxidant molecules [2].

Among AMPs, the hepcidin family of peptides plays an important role in the regulation of iron homeostasis in humans [3]. The liver expressed antimicrobial peptide, also known as Hepc25, is the only member of the hepcidin family that is known to be produced by humans $[4,5]$. Hepcidin also displays antimicrobial capabilities not only by inhibiting extracellular iron accumulation but also by direct lytic activity against several microorganisms. Indeed, these peptides have demonstrated antibacterial, antifungal and antiviral activities over several organisms [6-9]. These features make hepcidin peptides interesting candidates not only for antimicrobial treatments but also for several other biomedical applications $[8,10]$.

AMPs are generally obtained by direct isolation from natural sources, by chemical synthesis or by recombinant expression [11]. Direct isolation is a high-cost complex strategy as AMPs are present at very low concentrations in the natural organism and implies using harsh chemical procedures. The large-scale production of AMPs by chemical synthesis is characterized by prohibitive costs and is therefore restricted to small-scale productions. Recombinant expression, on the other hand, represents an alternative for large-scale production of these small peptides. As soon as the initial costs of cloning and optimization of production and purification are surpassed, the process 
can be up-scaled to economically feasible levels. Nevertheless, recombinant production of AMPs can be hampered by factors such as the peptide toxic effect for the producing host cells or degradation by proteases. Furthermore, purification is often cumbersome and time consuming. Fusion partners are often used to surpass these bottlenecks. Besides serving as tags for the purification processes, they can also reduce the peptide's associated toxicity and inhibit enzymatic degradation [11].

The use of elastin-like recombinamers (ELRs) as fusion partners represents a promising alternative to the traditional chromatographic purification systems. ELRs are a class of recombinant protein-based polymers based on the sequence of mammalian elastin. Apart from increasing solubility [12] the most relevant characteristic of ELRs is their inverse temperature transition behavior [13]. When in solution, the polymer acquires a disordered structure, but above its transition temperature $\left(T_{t}\right)$ the polymer self-assembles in a totally reversible process $[14,15]$. This behavior can be used for purification of recombinant proteins by hot and cold incubation and centrifugation steps, a process known as inverse transition cycling $[16,17]$.

In this work, we describe the production of recombinant human hepcidin Hep25c fused with the ELR A200. A200 is based on 200 repetitions of the pentamer sequence VPAVG and, in addition to the inverse temperature transition behavior, it also displays an acute thermal hysteresis $[15,17,18]$. In the presence of water, the polymer selfassembles into spherical microparticles at temperatures above a $T_{t}$ of $\sim 32{ }^{\circ} \mathrm{C}$ though the assembled structures only solubilize when cooled to $\sim 10^{\circ} \mathrm{C}$.

This is the first report on the production of recombinant human hepcidin using a nonchromatographic method for purification. Hep-A200, the recombinant fusion protein obtained, displays antibacterial, strongly supporting its use to fight microbial infections. 


\section{Materials and methods}

\section{Biological materials:}

Escherichia coli XL1-Blue and BL21(DE3) were used for the cloning and production steps. Pseudomonas aeruginosa ATCC10145, E. coli HB101, Staphylococcus aureus ATCC6538 and Bacillus subtilis 48886 were used in the antibacterial activity assays.

\section{Cloning:}

Hep-A200 construction $(\mathrm{MW}=87.9 \mathrm{kDa})$ was obtained using standard molecular genetic techniques by fusing the hepcidin sequence (Supplementary figure 1a) in-frame with the N-terminus of A200 (Supplementary figure 1b-c). Compatible NdeI and KpnI restriction sites were introduced into the chemically synthesized hepcidin (Hep25c) sequence $(\mathrm{MW}=2.8 \mathrm{kDa})$ by polymerase chain reaction $(\mathrm{PCR})$ and fused with the Nterminus of the ELR A200 polymer by ligation reaction. The ELR A200 gene has been previously cloned in a modified pET25b(+) (Novagen) expression plasmid [15]. The ligation reaction was transformed in E. coli XL1Blue for plasmid replication and storage. The final expression plasmid was confirmed by DNA sequencing and transformed into E. coli BL21(DE3) for recombinant protein production.

\section{Recombinant protein production and purification:}

E. coli BL21(DE3) cells transformed with the expression plasmid containing the HepA200 gene were grown in shake flasks for $22 \mathrm{~h}$ at $37^{\circ} \mathrm{C}, 200 \mathrm{rpms}$ using autoinduction medium (TBlac, yeast extract $24 \mathrm{~g}$, tryptone $12 \mathrm{~g}$, glycerol $5.04 \mathrm{~g}, \mathrm{~K}_{2} \mathrm{HPO}_{4} 12.54 \mathrm{~g}$, $\mathrm{KH}_{2} \mathrm{PO}_{4} 2.31 \mathrm{~g}$, lactose $2 \mathrm{~g}$ per liter) supplemented with $50 \mathrm{mg} / \mathrm{L}$ kanamycin, and a culture volume/flask volume ration of 1:4 [19]. The protein production levels were 
assessed by sodium dodecyl sulphate polyacrylamide gel electrophoresis (SDS-PAGE) with copper chloride staining $(0.3 \mathrm{M})$.

After production, cells were collected by centrifugation, resuspended in TE buffer ( 50 $\mathrm{mM}$ Tris-HCl, 1 mM EDTA, $\mathrm{pH}$ 8.0) and disrupted by sonication in a Sonics VCX 750. The $\mathrm{pH}$ was adjusted to 3.5 with $1 \mathrm{M} \mathrm{HCl}$ to precipitate endogenous $E$. coli contaminants and remove them by centrifugation [19]. The clear supernatant was then purified by inverse transition cycling (ITC) involving 4 cycles of hot $\left(37^{\circ} \mathrm{C}\right)$ and cold $(4$ ${ }^{\circ} \mathrm{C}$ ) incubation (60 min at each temperature) and centrifugation steps (30 min, $10000 \mathrm{x}$ g) as previously described for other ELRs $[15,17]$. The pure polymer fraction was lyophilized and stored at room temperature until use.

\section{Differential scanning calorimetry:}

The thermal transition events of Hep-A200 were characterized by differential scanning calorimetry (DSC) on a Mettler Toledo DSC 822e with calibration of both enthalpy and temperature achieved with standard indium and zinc samples. Solutions for DSC were prepared at $25 \mathrm{mg} / \mathrm{mL}$ in MilliQ water (mQ, Millipore) or PBS ( $\mathrm{NaCl} 8 \mathrm{~g}, \mathrm{KCl} 0.2 \mathrm{~g}$, $\mathrm{Na}_{2} \mathrm{HPO}_{4} 1.44 \mathrm{~g}, \mathrm{KH}_{2} \mathrm{PO}_{4} 0.24 \mathrm{~g}$, per liter, at $\mathrm{pH}$ 7.4). For analysis, $20 \mu \mathrm{L}$ of solutions were placed in hermetically sealed pans. A four-stage program was defined for each experiment: isothermal stage at $0{ }^{\circ} \mathrm{C}$ for $5 \mathrm{~min}$; heating stage at $5{ }^{\circ} \mathrm{C} / \mathrm{min}$ from $0{ }^{\circ} \mathrm{C}$ to $50{ }^{\circ} \mathrm{C}$; isothermal stage at $50{ }^{\circ} \mathrm{C}$ for $5 \mathrm{~min}$; and cooling stage at $5{ }^{\circ} \mathrm{C} / \mathrm{min}$ from $50{ }^{\circ} \mathrm{C}$ to $0{ }^{\circ} \mathrm{C}$. Liquid nitrogen $(50 \mathrm{~mL} / \mathrm{min})$ was used as cooler. Thermograms analysis and peak temperature calculations were completed using both STARe ${ }^{\mathrm{TM}}$ and OriginPro 8.1

(OriginLab, Northampton, MA) software. 
The size of Hep-A200 self-assembled particles was calculated by dynamic light scattering (DLS). Measurements were performed with filtered solutions at different concentrations $(0.001,0.01$ and $0.1 \mathrm{mg} / \mathrm{mL})$ and solvents (mQ water and PBS). Experiments were performed at $37^{\circ} \mathrm{C}$ on a Zetasizer Nano ZSP (Malvern) with 3 min equilibration time at $37^{\circ} \mathrm{C}$. Analysis was performed using 4 clear side disposable cuvettes with a $1 \mathrm{~cm}$ pathway length. Size was determined as the average of 15 measurements, with a defined $173^{\circ}$ backscatter angle and the number of runs automatically determined by the software. Data analysis was performed with Zetasizer Software 7.10 (Malvern).

For determination of the zeta-potential, filtered solutions of Hep-A200 at different concentrations $(0.001,0.01$ and $0.1 \mathrm{mg} / \mathrm{mL})$ in $\mathrm{mQ}$ water were analysed in disposable folded capillary cells (Malvern), with an equilibration time of 3 min at $37^{\circ} \mathrm{C}$. A total of 15 measurements with automatically determined runs (minimum of 10 , maximum of 100) were performed. Zeta-potential was obtained by analysis of the experimental data with the Smoluchowski model, using Zetasizer Software 7.10 (Malvern).

\section{Measurement of the antibacterial activity:}

Antibacterial activity was tested using a modified Kirby-Bauer agar diffusion method [20]. Briefly, holes were made in solid LB medium (yeast extract $0.5 \%$, tryptone $1 \%$, $\mathrm{NaCl} 0.5 \%$, agar $1.5 \%, \mathrm{w} / \mathrm{v}$ ) plates using an inverted Pasteur pipette and filled with 25 $\mu \mathrm{L}$ of Hep-A200 at $10 \%(\mathrm{w} / \mathrm{v})$ concentration, corresponding to $79.5 \mu \mathrm{g}$ of hepcidin (hepcidin represents $3.18 \%$ of the full Hep-A200), in testing solution $(0.87 \% \mathrm{NaCl}$, $0.05 \%$ acetic acid). Overnight cultures of $P$. aeruginosa, E. coli, $S$. aureus and $B$. subtilis were diluted in LB medium with agar at $0.8 \%(\mathrm{w} / \mathrm{v})$ to a final cell density of $1 \mathrm{x}$ $10^{6}$ cells $/ \mathrm{mL}$, layered on the LB plates and incubated overnight at $37^{\circ} \mathrm{C}$. Holes filled 
with $25 \mu \mathrm{L}$ of testing solution and kanamycin impregnated disks $(30 \mu \mathrm{g}, \mathrm{BD}$ Biosciences) were used as negative and positive controls, respectively. After overnight incubation at $37^{\circ} \mathrm{C}$, the diameters of growth inhibitory zones were measured.

\section{Cell culture and cytotoxicity evaluation:}

BJ-5ta (telomerase-immortalized normal human skin fibroblasts) cell line was obtained from the American Type Culture Collection (ATCC, through LGC standards, Teddington, Middlesex, UK). Cells were cultured at $37^{\circ} \mathrm{C}, 5 \% \mathrm{CO}_{2}$, in humidified environment and according to ATCC recommendations: BJ-5ta medium - 4 parts of Dulbecco's modified Eagle's medium containing 4 mM L-glutamine, 4.5 g/L glucose, $1.5 \mathrm{~g} / \mathrm{L}$ sodium bicarbonate, and 1 part of Medium 199, supplemented with $10 \%(\mathrm{v} / \mathrm{v})$ of fetal bovine serum, $1 \%(\mathrm{v} / \mathrm{v})$ penicillin/streptomycin solution and $10 \mu \mathrm{g} / \mathrm{mL}$ hygromycin B.

Sample cytotoxicity was assessed on BJ-5ta cell line by means of a direct contact assay. Lyophilized Hep-A200 was dissolved in culture medium to a final concentration of $2.5 \%(\mathrm{w} / \mathrm{v})$ and incubated for $24 \mathrm{~h}$ at $37^{\circ} \mathrm{C}, 5 \% \mathrm{CO}_{2}$ in a humidified environment. Simultaneously, $100 \mu \mathrm{L}$ of cell suspension $\left(6.6 \times 10^{4}\right.$ cells $\left./ \mathrm{mL}\right)$ were seeded and cultured in surface treated 96-well plates (Nunclon polystyrene 96-well MicroWell, Thermo Scientific). After $24 \mathrm{~h}$, cell culture medium was replaced with the medium containing Hep-A200. Cell viability was then evaluated after 24 and $72 \mathrm{~h}$, using the MTS assay (CellTiter 96® Aqueous One Solution Cell Proliferation, Promega) according to manufacturer's instructions. Briefly, cells in fresh culture medium were incubated with MTS solution for $2 \mathrm{~h}$ at $37{ }^{\circ} \mathrm{C}$ followed by absorbance reading at $490 \mathrm{~nm}$ with standard culture medium used as blank measurement. DMSO 30\% and cells cultured in standard culture medium at the conditions tested were used as negative and 
positive controls for cell viability, respectively. Results were expressed as percentage of proliferation in relation to the positive control (set as $100 \%$ proliferation).

\section{Statistical analysis:}

One-way analysis of variance (ANOVA) with Bonferroni's post-test was carried out with GraphPad Prism 5 software to compare the means of different data sets within each experiment. A value of $\mathrm{p}<0.05$ was considered to be statistically significant. All experiments were performed in triplicate.

\section{Results}

Recombinant protein production and purification:

Hep-A200 was constructed by inclusion of $N d e \mathrm{I}$ and $K p n I$ restriction sites in the Hepc25 DNA sequence by PCR and ligated to an expression plasmid containing the A200 gene. The recombinant polymer Hep-A200 was successfully produced in E. coli BL21(DE3) by auto-induction with production expression levels being monitored by SDS-PAGE (figure 1a). The protein was purified by inverse transition cycling (ITC) by exploring the thermoresponsiveness of the ELR-tag using hot and cold incubation and centrifugation steps (figure 1b). This process allowed to obtain a fully purified polymer fraction of Hep-A200 with final volumetric productivities of $50 \mathrm{mg} / \mathrm{L}$. The alteration of the expected gel mobility of the recombinant protein at higher molecular weight is attributed to the hydrophobic nature of these recombinant protein-based polymers [15,21-23]. To further evaluate if the ITC-purified hepcidin was able to form disulfide bridges, the content of free cysteines was measured by Ellman's reagent 
(Supplementary information) with results demonstrating that S-S bonds are formed without the need of additional steps.

\section{Characterization of the thermal changes of Hep-A200:}

The thermal events of Hep-A200 were analyzed by DSC in order to determine the transition temperature $\left(T_{\mathrm{t}}\right)$ of the self-assembling process. Figure $2 \mathrm{a}$ displays the thermogram of Hep-A200 samples in mQ water and PBS upon heating, showing the characteristic endothermic peak of the phase transition. The transition temperatures were calculated by the peak center of the endothermic curves and determined as $32.3{ }^{\circ} \mathrm{C}$ and $29.7{ }^{\circ} \mathrm{C}$ for the samples in $\mathrm{mQ}$ water and PBS, respectively. The thermal hysteresis behavior found for ELRs based on the VPAVG sequence $[15,18,24]$ is clearly observed by comparing with the cooling DSC curve (Figure 2b). The exothermic peaks at $15.5^{\circ} \mathrm{C}$ (sample in $\mathrm{mQ}$ water) and $14.6{ }^{\circ} \mathrm{C}$ (sample in PBS) are attributed to the resolubilisation of Hep-A200 which are centered at a lower temperature than the calculated $T_{t}$, indicating that the hysteresis behavior of A200 is maintained in Hep-A200. During the phase transition process (temperatures above $T_{\mathrm{t}}$ ), Hep-A200 self-assembles into spherical or slightly ellipsoidal particles that aggregate (Figure 3). Hep-A200 selfassembled structures in mQ water and PBS were characterized by DLS at $37^{\circ} \mathrm{C}$ using different concentrations. The mean particle size of the samples was determined by the Z-average, defined as the harmonic intensity averaged particle diameter, which is the optimized value obtained after all measurements for relatively monodisperse samples. For all the concentrations tested, the samples in mQ water showed no variation in size distribution, with Z-average values of $147.5 \pm 3.45,154.2 \pm 1.73$ and $147.2 \pm 2.59 \mathrm{~nm}$ for the concentrations of $0.001,0.01$ and $0.1 \mathrm{mg} / \mathrm{mL}$, respectively (figure $4 \mathrm{a}$ ). As for the samples in PBS, the Z-average showed to change with the concentration, reaching 
values of $108.5 \pm 14.95,674.3 \pm 160.1$ and $1283 \pm 243.1 \mathrm{~nm}$ for the concentrations of $0.001,0.01$ and $0.001 \mathrm{mg} / \mathrm{mL}$, respectively (figure $4 \mathrm{~b}$ ). The polydispersity index (PDI) remained relatively low for all the mQ water samples with values of $0.113 \pm 0.016$, $0.071 \pm 0.017$ and $0.078 \pm 0.020$ for the concentrations of $0.001,0.01$ and $0.1 \mathrm{mg} / \mathrm{mL}$, respectively (figure 4a). Regarding the samples in PBS, the PDI showed to increase with concentration, displaying values of $0.170 \pm 0.018,0.354 \pm 0.074$ and $0.560 \pm 0.087$ for the concentrations of $0.001,0.01$ and $0.1 \mathrm{mg} / \mathrm{mL}$, respectively, suggesting aggregation.

When analyzing the DLS measurements over time, it became noticeable that aggregation was not only directly related with concentration but also to the time that Hep-A200 samples were kept at $37^{\circ} \mathrm{C}$. Figure 5a-d correlates the mean particle size with the time that the solution was maintained at $37^{\circ} \mathrm{C}$. None of the samples in $\mathrm{mQ}$ water exhibited remarkable differences in the mean size, showing a trend to maintain the initial size value. In opposition, the samples in PBS demonstrated a dramatic change in the mean size over the time course of the experiment. At $0.001 \mathrm{mg} / \mathrm{mL}$, the HepA200 mQ water sample varied from $140.5 \pm 61.35$ to $146 \pm 59.64 \mathrm{~nm}$ whereas the PBS sample ranged from $85.6 \pm 27.49$ to $131.8 \pm 67.01 \mathrm{~nm}$ (figure $5 \mathrm{a}$ ). With a concentration of $0.01 \mathrm{mg} / \mathrm{mL}$, the size of the mQ water sample varied from $158.1 \pm 43.72$ to $154.9 \pm$ 46.11 while the PBS sample increased from $644.7 \pm 192.8$ to $1742 \pm 551.5 \mathrm{~nm}$ (figure 5b). Finally, with a concentration of $0.1 \mathrm{mg} / \mathrm{mL}$, the mQ sample varied from $154.1 \pm$ 54.28 to $147.9 \pm 46.44 \mathrm{~nm}$ and the PBS from $1403 \pm 824.4$ to $2810 \pm 699.5 \mathrm{~nm}$ (figure5c).

Due to the high conductivity of PBS it was not possible to correctly measure the surface charge by zeta potential. The measurements of samples in $\mathrm{mQ}$ water show that the zeta potential increases with an increasing concentration of Hep-A200. The values obtained 
were of $0.19 \pm 1.3 \mathrm{mV}, 8.0 \pm 1.3 \mathrm{mV}$ and $13.6 \pm 0.745 \mathrm{mV}$ for $0.001,0.01$ and 0.1 $\mathrm{mg} / \mathrm{mL}$, respectively.

Antibacterial activity of Hep-A200:

The antibacterial activity of Hep-A200 at a concentration of $10 \%(\mathrm{w} / \mathrm{v})$ was tested against $P$. aeruginosa, E. coli, B. subtilis and $S$. aureus by a modified Kirky Bauer disk diffusion assay (figure 6a). Hep-A200 induced the formation of clear inhibitions halos for all the bacteria tested with the size of the halos varying between species. The negative control produced no halos and kanamycin, here used as positive control, produced the halos with higher diameter. The measured inhibition halos diameters were $7.3 \pm 2.0,6.2 \pm 3.4,14.1 \pm 2.03$ and $6.7 \pm 2.3 \mathrm{~mm}$ for $P$. aeruginosa, B. subtilis, E. coli and $S$. aureus, respectively (Figure 6b). The values obtained are lower than those obtained for kanamycin disks, but a direct correlation with the halo sizes from kanamycin and Hep-A200 is encountered. The bigger the halo of kanamycin against a certain bacterial species, the bigger the halo of Hep-A200 against the same bacteria.

Cytotoxicity of Hep-A200 solutions:

The in vitro cytotoxicity of $2.5 \%(\mathrm{w} / \mathrm{v})$ Hep-A200 solutions was evaluated by a direct contact assay using the BJ-5ta cell line (figure 7). Interestingly, higher concentrations of Hep-A200 in culture medium could not be used as higher concentrations showed to form some kind of matrix (data not shown), suggesting a mechanism of gelation that will be investigated in the future. The solutions of Hep-A200 showed no significant cytotoxicity after $24 \mathrm{~h}$ of incubation, leading to $95.1 \pm 6.6 \%$ cell viability, when compared to the control. At $72 \mathrm{~h}$, the $\%$ proliferation in relation to the control was of $81.2 \pm 3.4 \%$ 


\section{Discussion}

In this study, we describe the construction, recombinant production and assessment of the antibacterial activity of human hepcidin fused with the ELR A200. The genetic construction was transformed into E. coli BL21(DE3) and Hep-A200 was produced by batch fermentation by means of auto-induction. The introduction of the hepcidin sequence in the N-terminus of A200 enabled higher volumetric productivity of A200, when compared to the production of the polymer alone [15]. While the reasons underlying these differences remain to be fully understood, the fusion order of the construct, protein-ELR or ELR-protein, showed to greatly influence the expression levels and activity of fusion proteins [25]. This has been suggested to be a consequence of lower translational levels of the mRNA in the ELR-protein direction, or of intracellular degradation due to larger misfolded conformers of ELR-protein compared to protein-ELR constructs [25]. After purification by ITC, the final volumetric productivity of Hep-A200 was of $50 \mathrm{mg} / \mathrm{L}$, representing a 2 to 4 fold improvement compared to literature [26-28]. Recombinant hepcidin is often produced in E. coli in inclusion bodies that imply the use of cumbersome resolubilisation procedures prior to purification by chromatography $[26,27,29]$. Noteworthy, Hep-A200 was produced in the soluble fraction thus avoiding additional intermediate steps. Furthermore, the use of the ELR tag allowed high protein recovery during purification without the need of complex, expensive and time-consuming chromatographic purification.

DSC analysis was employed to characterize the inverse temperature transition behaviour of Hep-A200 and calculate the associated transition temperatures (figure 2). The characteristic lower $T_{t}$ observed for the PBS sample compared to mQ water (figure 2a) 
has already been observed for other ELRs in salt conditions (i.e. $\mathrm{NaCl}$ ) $[15,24,30]$, and shown to influence the ELR self-assembly process $[31,32]$. In fact, it was demonstrated that the $T_{t}$ of ELRs changes in the presence of $\mathrm{NaCl}$ as a consequence of a better formation of water structures surrounding the apolar moieties of the polymer chain in the extended state [33]. During the cooling stage of DSC (figure 2b) is observed the thermal hysteresis associated with the resolubilisation process of Hep-A200; the exothermic peaks resulting from this process appear at lower temperatures than the calculated $T_{t}$ for both solvents. This behaviour is characteristic of VPAVG-based polymers and is a consequence of the rigid and compact structure formed above the $T_{t}$ by intramolecular hydrogen bonds between the amide groups $[15,24,34]$. In this state, a great majority of the amide groups are directly bound together, blocking the penetration of water molecules between the chains and resulting in the hysteresis behaviour [34]. Interestingly, the exothermic peaks observed during cooling are much narrower than those previously observed for other A200-based proteins [15,17,24]. This could illustrate the resolubilisation process in Hep-A200 as a more acute behaviour than for the other A200-based constructs and attributed to the presence of hepcidin. As aforementioned, at temperatures above $T_{t}$ there is less water bound to the amide groups. This results in a compact structure causing the formation of stable particle suspensions $[15,24,34]$. The size of the self-assembled Hep-A200 structures was analysed by DLS (figure 4) revealing distinct patterns according to the solution used, $\mathrm{mQ}$ water or PBS. The values obtained with $\mathrm{mQ}$ water revealed that size is generally maintained independently of the concentration of Hep-A200 (figure 4a). However, HepA200 in PBS showed an aggregation profile at increasing concentrations, reaching Zaverage values approximately 6 - and 12 -fold larger. Noteworthy is that by comparing 
the particle size at the lowest concentration $(0.001 \mathrm{mg} / \mathrm{mL})$, the PBS sample exhibited a smaller size than the mQ water sample.

To further study the aggregation process of Hep-A200 upon heating, DLS measurements were taken over time at $37^{\circ} \mathrm{C}$ (figure 5). The Z-average of the selfassembled structures for the different concentrations of Hep-A200 in mQ water were similar throughout the experiment. In contrast, the particles in PBS showed a dramatic increase of size over time, for all the concentrations tested. The presence of salts may cause this change in behaviour, where particles charge may be shifting and a higher level of aggregation is induced. Analysis of the coefficients of determination $\left(\mathrm{r}^{2}\right)$ for all concentrations in PBS reveals a loss of linear correlation as concentrations increases (figure 4d). This result is most likely due to the increasing polydispersity of the microaggregates, leading to a not so linear size evolution. Similarly to the Z-average, the PDI of the particles in the PBS samples showed to increase with concentration further supporting the occurrence of particle aggregation. A more systematic study on the fundamental basis of the self-assembling process by determining the assembling kinetics of VPAVG-based ELRs in the presence of salts could shed some light into this issue but, it is beyond the scope of this article.

The zeta-potential of the particles in $\mathrm{mQ}$ water showed to increase with increasing concentrations of Hep-A200. Given that the VPAVG tag is essentially neutral, the positive $\mathrm{mV}$ value of the particles is most likely due to the presence of hepcidin in the corona of the self-assembled particles. Interestingly, the increase of the zeta-potential with increasing concentrations of Hep-A200 was unexpected. Especially considering that the particle size is maintained over the range of concentrations tested.

The antimicrobial activity of Hep-A200 in solution was tested against four bacterial species namely, E. coli (Gram-negative), P. aeruginosa (Gram-negative), S. aureus 
(Gram-positive) and B. subtilis (Gram-positive). The presence of clear inhibition halos (figure 6) indicates that Hep-A200 is highly effective in exerting an antibacterial action being more effective against Gram-positive than Gram-negative bacteria.

As a result of the antimicrobial performance, the cytotoxicity of Hep-A200 was

evaluated by direct contact using normal human skin fibroblasts (BJ-5ta cell line). This parameter is of great importance considering the potential application of a material for biomedical purposes. Results of the exposure of fibroblasts to the Hep-A200 particles revealed no significant cytotoxicity after $72 \mathrm{~h}$ of contact.

\section{Conclusion}

Recombinant Hep-A200 was successfully produced in E. coli and showed to retain the same thermoresponsive properties as other A200-based polymers. This facilitated purification by the use of ITC and allowed high protein recovery during purification without the need of cumbersome, expensive and time-consuming purification techniques such as IMAC.

By inducing the phase-transition behaviour at temperatures above its $T_{t}$ and in the presence of water, it was possible to observe the formation of a monodisperse population of self-assembled nano-sized particles that are stable in solution. The use of a salt solution showed to greatly influence both the thermoresponsiveness of the recombinant fusion protein as well as the self-assembling process. Interestingly, in the presence of PBS, the self-assembled structures showed to form a polydisperse population of particles that aggregate. The size of the microaggregates showed to be directly influenced by the concentration of Hep-A200 and by the time of incubation at $37^{\circ} \mathrm{C}$. The recombinant soluble protein displayed antibacterial activity against a range 
of Gram-negative and Gram-positive bacteria. Furthermore, besides its obvious advantage for purification, the use of the ELR-tag maintained the activity of the antimicrobial peptide without the need of additional refolding procedures and allowed to be recombinantly produced in E. coli without major toxicity to the host. Finally, the self-assembled antimicrobial particles revealed no significant cytotoxicity effects in in vitro cultures of normal human skin fibroblasts.

This study greatly supports the use of antimicrobial peptides produced by recombinant DNA technology for the biomedical/biotechnology industry. It is possible to scale-up the recombinant production and the implementation of a non-chromatographic purification methodology greatly contributes to reduce costs.

\section{Further Discussion and Application}

The thermal responsiveness of A200 can also be explored for the production of stable microparticles that can be used to encapsulate active substances using mild conditions (e.g. water and $37^{\circ} \mathrm{C}$ ). For instance, poly(VPAVG) have been used for the encapsulation of bone morphogenetic protein-2 and -14 (BMP-2, BMP-14) [35,36] and the drug dexamethasone phosphate (DMP) [24]. Furthermore, poly(VPAVG) microparticles demonstrated excellent biocompatibility [37]. When comparing the DLS results with SEM, it is evident the strong shrinkage experienced by the microparticles during the drying process, suggesting that the swollen Hep-A200 particles have approximately $70 \%$ water content. This provides an opportunity to develop a platform for the development of antimicrobial drug release systems with the ability to encapsulate active substances at relatively high levels. 


\section{Funding}

This work was supported by national funds through the FCT I.P. and by the ERDF through the COMPETE2020 - Programa Operacional Competitividade e Internacionalização (POCI) [strategic program UID/BIA/04050/2013 (POCI-01-0145FEDER-007569)]. The present work was also supported by FCT within the ERA-NET IB, project FunBioPlas [grant number ERA-IB-15-089 and FCT reference ERA-IB-26/0004/2014]. AMPereira work was funded by DP_AEM and FCT [ grant $\mathrm{PD} / \mathrm{BD} / 113811 / 2015]$. This article is a result of the project EcoAgriFood [NORTE-010145-FEDER-000009], supported by Norte Portugal Regional Operational Programme (NORTE 2020), under the PORTUGAL 2020 Partnership Agreement, through the European Regional Development Fund (ERDF).

\section{References}

[1] Brogden KA. Antimicrobial peptides: pore formers or metabolic inhibitors in bacteria? Nat Rev Microbiol 2005;3:238-50. doi:10.1038/nrmicro1098.

[2] Pasupuleti M, Schmidtchen A, Malmsten M. Antimicrobial peptides: key components of the innate immune system. Crit Rev Biotechnol 2012;32:143-71. doi:10.3109/07388551.2011.594423.

[3] Ganz T, Nemeth E. Hepcidin and iron homeostasis. Biochim Biophys Acta - Mol Cell Res 2012;1823:1434-43. doi:10.1016/j.bbamcr.2012.01.014.

[4] Park CH, Valore E V., Waring AJ, Ganz T. Hepcidin, a Urinary Antimicrobial Peptide Synthesized in the Liver. J Biol Chem 2001;276:7806-10. doi:10.1074/jbc.M008922200. 
[5] Farnaud S, Patel A, Evans RW. Modelling of a metal-containing hepcidin. BioMetals 2006;19:527-33. doi:10.1007/s10534-005-5883-z.

[6] Krause A, Neitz S, Mägert HJ, Schulz A, Forssmann WG, Schulz-Knappe P, et al. LEAP-1, a novel highly disulfide-bonded human peptide, exhibits antimicrobial activity. FEBS Lett 2000;480:147-50. doi:10.1016/S00145793(00)01920-7.

[7] Liu H, Trinh T Le, Dong H, Keith R, Nelson D, Liu C. Iron Regulator Hepcidin Exhibits Antiviral Activity against Hepatitis C Virus. PLoS One 2012;7:3-10. doi:10.1371/journal.pone.0046631.

[8] Michels K, Nemeth E, Ganz T, Mehrad B. Hepcidin and Host Defense against Infectious Diseases. PLOS Pathog 2015;11:e1004998. doi:10.1371/journal.ppat.1004998.

[9] Houamel D, Ducrot N, Lefebvre T, Daher R, Moulouel B, Sari M -a., et al. Hepcidin as a Major Component of Renal Antibacterial Defenses against Uropathogenic Escherichia coli. J Am Soc Nephrol 2015:1-12. doi:10.1681/ASN.2014101035.

[10] Liu J, Sun B, Yin H, Liu S. Hepcidin: A Promising Therapeutic Target for Iron DisordersA Systematic Review. Medicine (Baltimore) 2016;95:e3150. doi:10.1097/MD.0000000000003150.

[11] Parachin NS, Mulder KC, Viana AAB, Dias SC, Franco OL. Expression systems for heterologous production of antimicrobial peptides. Peptides 2012;38:446-56. doi:10.1016/j.peptides.2012.09.020.

[12] Araújo R, Silva C, Machado R, Casal M, Cunha AM, Rodriguez-Cabello JC, et al. Proteolytic Enzyme Engineering: A Tool for Wool. Biomacromolecules 
2009;10:1655-61. doi:10.1021/bm9002943.

[13] Floss DM, Schallau K, Rose-John S, Conrad U, Scheller J. Elastin-like polypeptides revolutionize recombinant protein expression and their biomedical application. Trends Biotechnol 2010;28:37-45.

doi:10.1016/j.tibtech.2009.10.004.

[14] Girotti A, Fernández-Colino A, López IM, Rodríguez-Cabello JC, Arias FJ. Elastin-like recombinamers: biosynthetic strategies and biotechnological applications. Biotechnol J 2011;6:1174-86. doi:10.1002/biot.201100116.

[15] Machado R, Ribeiro AJ, Padrão J, Silva D, Nobre A, Teixeira JA, et al. Exploiting the Sequence of Naturally Occurring Elastin: Construction, Production and Characterization of a Recombinant Thermoplastic Protein-Based Polymer. J Nano Res 2009;6:133-45.

doi:10.4028/www.scientific.net/JNanoR.6.133.

[16] Hassouneh W, Christensen T, Chilkoti A. Elastin-Like Polypeptides as a Purification Tag for Recombinant Proteins. Curr Protoc Protein Sci 2010:1-16. doi:10.1002/0471140864.ps0611s61.

[17] da Costa A, Machado R, Ribeiro A, Collins T, Thiagarajan V, Neves-Petersen MT, et al. Development of Elastin-Like Recombinamer Films with Antimicrobial Activity. Biomacromolecules 2015;16:625-35. doi:10.1021/bm5016706.

[18] Reguera J, Lagarón JM, Alonso M, Reboto V, Calvo B, Rodríguez-Cabello JC. Thermal Behavior and Kinetic Analysis of the Chain Unfolding and Refolding and of the Concomitant Nonpolar Solvation and Desolvation of Two Elastin-like Polymers. Macromolecules 2003;36:8470-6. doi:10.1021/ma034572q.

[19] Machado R, Azevedo-Silva J, Correia C, Collins T, Arias FJ, Rodríguez-Cabello 
$\mathrm{JC}$, et al. High level expression and facile purification of recombinant silkelastin-like polymers in auto induction shake flask cultures. AMB Express 2013;3:11. doi:10.1186/2191-0855-3-11.

[20] Bauer AW, Perry DM, Kirby WMM. Single-Disk Antibiotic-Sensitivity Testing of Staphylococci. AMA Arch Intern Med 1959;104:208. doi:10.1001/archinte.1959.00270080034004.

[21] McPherson DT, Morrow C, Minehan DS, Wu J, Hunter E, Urry DW. Production and purification of a recombinant elastomeric polypeptide, G-(VPGVG)19VPGV, from Escherichia coli. Biotechnol Prog 1992;8:347-52. doi:10.1021/bp00016a012.

[22] Lyons RE, Lesieur E, Kim M, Wong DCC, Huson MG, Nairn KM, et al. Design and facile production of recombinant resilin-like polypeptides: Gene construction and a rapid protein purification method. Protein Eng Des Sel 2007;20:25-32. doi:10.1093/protein/gzl050.

[23] Teng W, Cappello J, Wu X. Recombinant silk-elastinlike protein polymer displays elasticity comparable to elastin. Biomacromolecules 2009;10:3028-36. doi:10.1021/bm900651g.

[24] Herrero-Vanrell R, Rincón a. C, Alonso M, Reboto V, Molina-Martinez IT, Rodríguez-Cabello JC. Self-assembled particles of an elastin-like polymer as vehicles for controlled drug release. J Control Release 2005;102:113-22. doi:10.1016/j.jconrel.2004.10.001.

[25] Christensen T, Amiram M, Dagher S, Trabbic-Carlson K, Shamji MF, Setton LA, et al. Fusion order controls expression level and activity of elastin-like polypeptide fusion proteins. Protein Sci 2009;18:1377-87. doi:10.1002/pro.157. 
[26] Gagliardo B, Faye A, Jaouen M, Deschemin JC, Canonne-Hergaux F, Vaulont S, et al. Production of biologically active forms of recombinant hepcidin, the ironregulatory hormone. FEBS J 2008;275:3793-803. doi:10.1111/j.17424658.2008.06525.x.

[27] Zhang H, Yuan Q, Zhu Y, Ma R. Expression and preparation of recombinant hepcidin in Escherichia coli. Protein Expr Purif 2005;41:409-16. doi:10.1016/j.pep.2005.03.003.

[28] Gomes SC, Leonor IB, Mano JF, Reis RL, Kaplan DL. Antimicrobial functionalized genetically engineered spider silk. Biomaterials 2011;32:4255-66. doi:10.1016/j.biomaterials.2011.02.040.

[29] Gerardi G, Biasiotto G, Santambrogio P, Zanella I, Ingrassia R, Corrado M, et al. Recombinant human hepcidin expressed in Escherichia coli isolates as an iron containing protein. Blood Cells, Mol Dis 2005;35:177-81. doi:10.1016/j.bcmd.2005.06.002.

[30] Luan C-H, Parker TM, Prasad KU, Urry DW. Differential scanning calorimetry studies of $\mathrm{NaCl}$ effect on the inverse temperature transition of some elastin-based polytetra-, polypenta-, and polynonapeptides. Biopolymers 1991;31:465-75. doi:10.1002/bip.360310502.

[31] Urry DW. What Sustains Life? Boston, MA: Birkhäuser Boston; 2006. doi:10.1007/978-0-8176-4562-5.

[32] Cho Y, Zhang Y, Christensen T, Sagle LB, Chilkoti A, Cremer PS. Effects of hofmeister anions on the phase transition temperature of elastin-like polypeptides. J Phys Chem B 2008;112:13765-71. doi:10.1021/jp8062977.

[33] Reguera J, Urry DW, Parker TM, McPherson DT, Rodríguez-Cabello JC. Effect 
of $\mathrm{NaCl}$ on the exothermic and endothermic components of the inverse temperature transition of a model elastin-like polymer. Biomacromolecules 2007;8:354-8. doi:10.1021/bm0609361.

[34] Schmidt P, Dybal J, Rodriguez-Cabello JC, Reboto V. Role of water in structural changes of poly(AVGVP) and poly(GVGVP) Studied by FTIR and Raman spectroscopy and ab initio calculations. Biomacromolecules 2005;6:697-706. doi:10.1021/bm049461t.

[35] Bessa PC, Machado R, Nürnberger S, Dopler D, Banerjee A, Cunha AM, et al. Thermoresponsive self-assembled elastin-based nanoparticles for delivery of BMPs. J Control Release 2010;142:312-8. doi:10.1016/j.jconrel.2009.11.003.

[36] Machado R, Bessa PC, Reis RL, Rodriguez-Cabello JC, Casal M. Elastin-Based Nanoparticles for Delivery of Bone Morphogenetic Proteins. Nanoparticles Biol. Med. Methods Protoc., vol. 906, 2012, p. 353-63.

[37] Rincón AC, Molina-Martinez IT, de las Heras B, Alonso M, Baílez C, Rodríguez-Cabello JC, et al. Biocompatibility of elastin-like polymer poly(VPAVG) microparticles: in vitro and in vivo studies. J Biomed Mater Res Part A 2006;78A:343-51. doi:10.1002/jbm.a.30702. 


\section{Figure captions:}

Figure 1 - SDS-PAGE of a) Hep-A200 production in E. coli BL21(DE3), after $22 \mathrm{~h}$ at $37^{\circ} \mathrm{C}, 200 \mathrm{rpm}$ in TBlac medium; Ø corresponds to the empty E. coli BL21(DE3). b) The recombinant polymer Hep-A200 was purified by inverse transition cycling. After sonication the lysate was adjusted to $\mathrm{pH} 3.5$ and centrifuged. Improved purification was obtained after 5 purification cycles using hot and cold centrifugation steps (lanes 2-6). Gels were stained with $0.3 \mathrm{M}$ copper chloride. MWM corresponds to the molecular weight marker; Figure was assembled from pictures of different gels. No modifications were made other than cutting, pasting and resizing.

Figure 2 - DSC thermograms of Hep-A200 during the heating (a) and cooling (b) stages.

Figure 3 - SEM of the particle aggregates formed by precipitation of Hep-A200 in water after heating at $37{ }^{\circ} \mathrm{C}$. Hep-A200 presents a $T_{\mathrm{t}}$ of $32.3{ }^{\circ} \mathrm{C}$. The smaller size of the particles when compared with DLS is due to the dehydration step in sample preparation.

Figure 4 - Dynamic light scattering measurements of Hep-A200 self-assembled structures: a) Size distribution histogram of Hep-A200 at different concentrations dissolved in $\mathrm{mQ}$ water, and respective table with Z-average size and polydispersity index (PDI); b) ) Size distribution histogram of Hep-A200 solution at different concentrations dissolved in PBS and respective table with Z-average size and PDI.

Figure 5 - Time course size distribution of Hep-A200 at $37^{\circ} \mathrm{C}$ and concentrations of a) 0.001, b) 0.01 and c) $0.1 \mathrm{mg} / \mathrm{mL}$ in $\mathrm{mQ}$ water or PBS; d) Correlation coefficient of the samples in PBS. 
Figure 6 - Antibacterial activity of Hep-A200 against four bacterial species. a) inhibition halos obtained with a modified Kirby-Bauer diffusion assay of Hep-A200 samples $(10 \% \mathrm{w} / \mathrm{v})$ against $P$. aeruginosa, E. coli, B. subtilis and $S$. aureus, at $37^{\circ} \mathrm{C}, 18$ h; b) measurement of the inhibition halos obtained with the modified Kirby-Bauer assay of Hep-A200 and Kanamycin samples

Figure 7 - Cytotoxicity evaluation of Hep-A200 after 24 and $72 \mathrm{~h}$ of indirect contact on normal human skin fibroblasts (BJ-5ta cell line) using the MTS assay. Results are expressed as $\%$ cell viability in relation to the control. Bars represent mean $\pm \mathrm{SD}$ (ns, nonsignificant; $* * * * p<0.0001)$. 
a

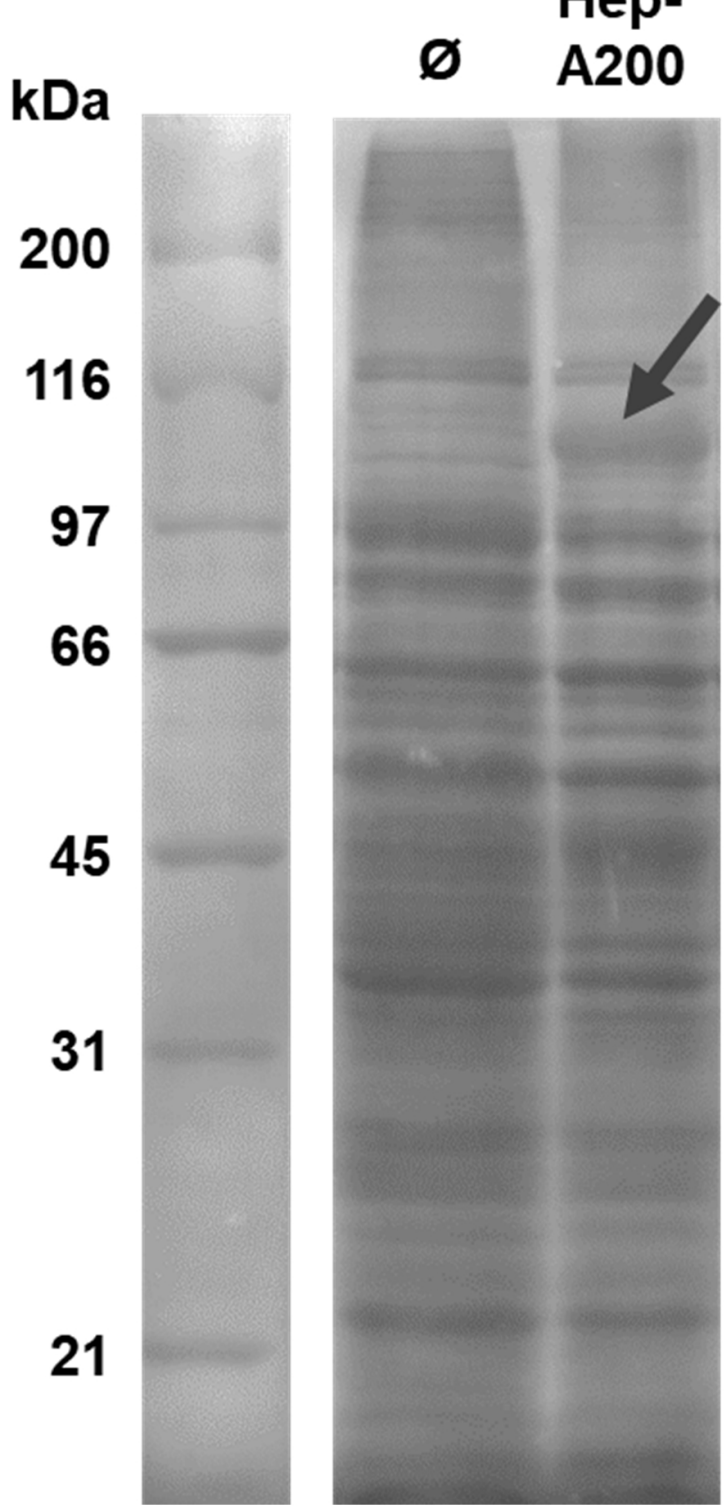

b

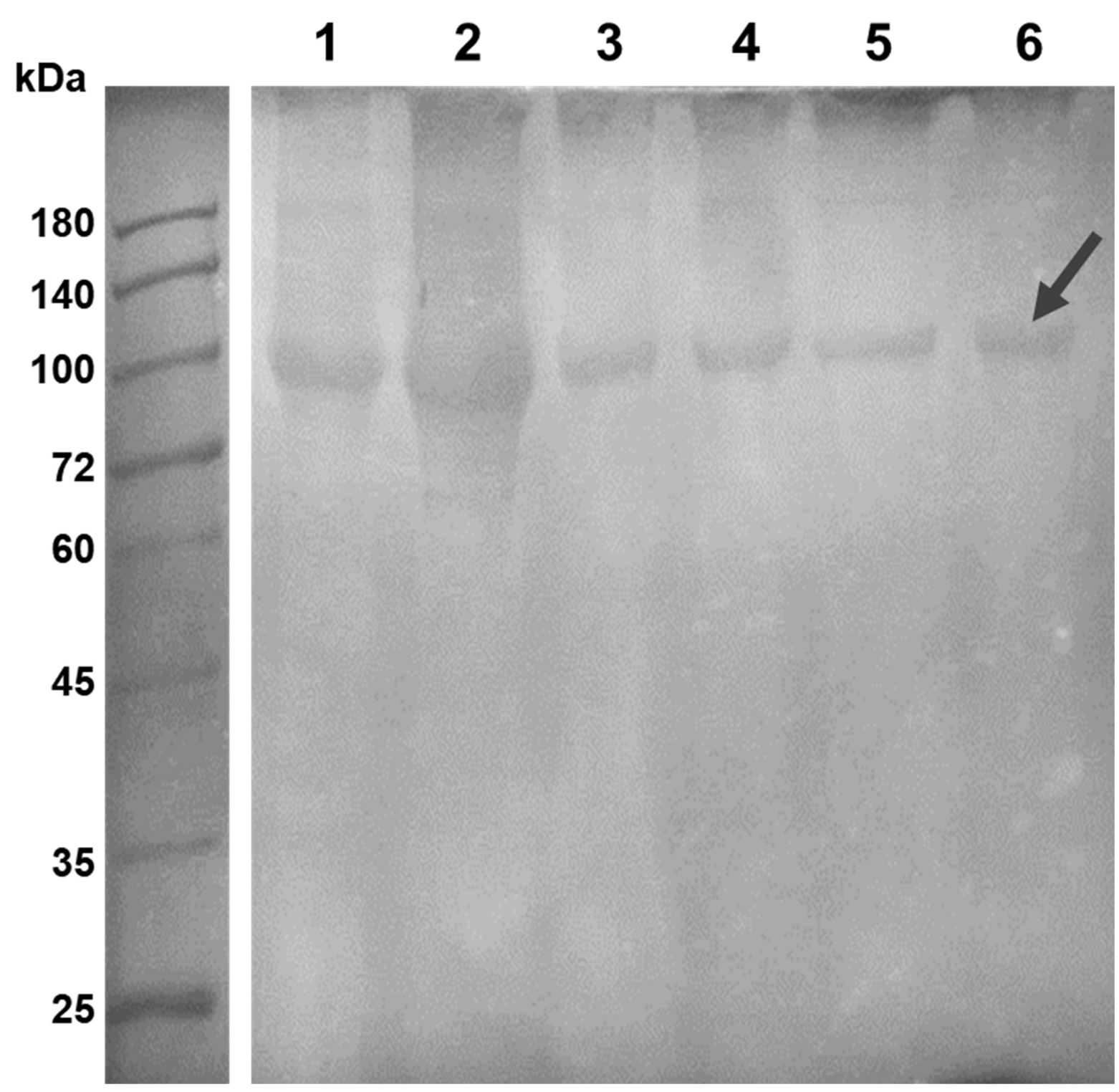




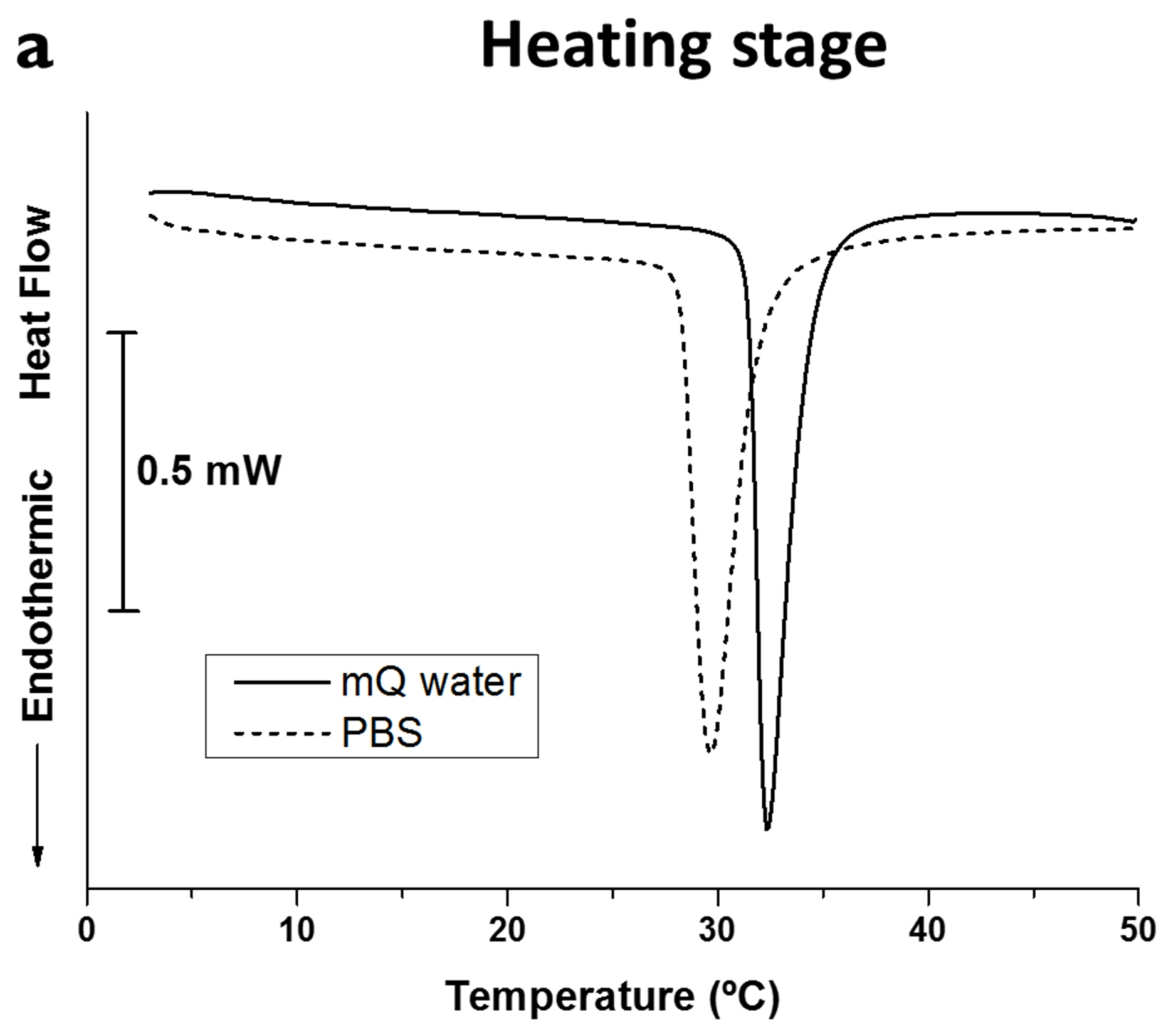

b Cooling stage

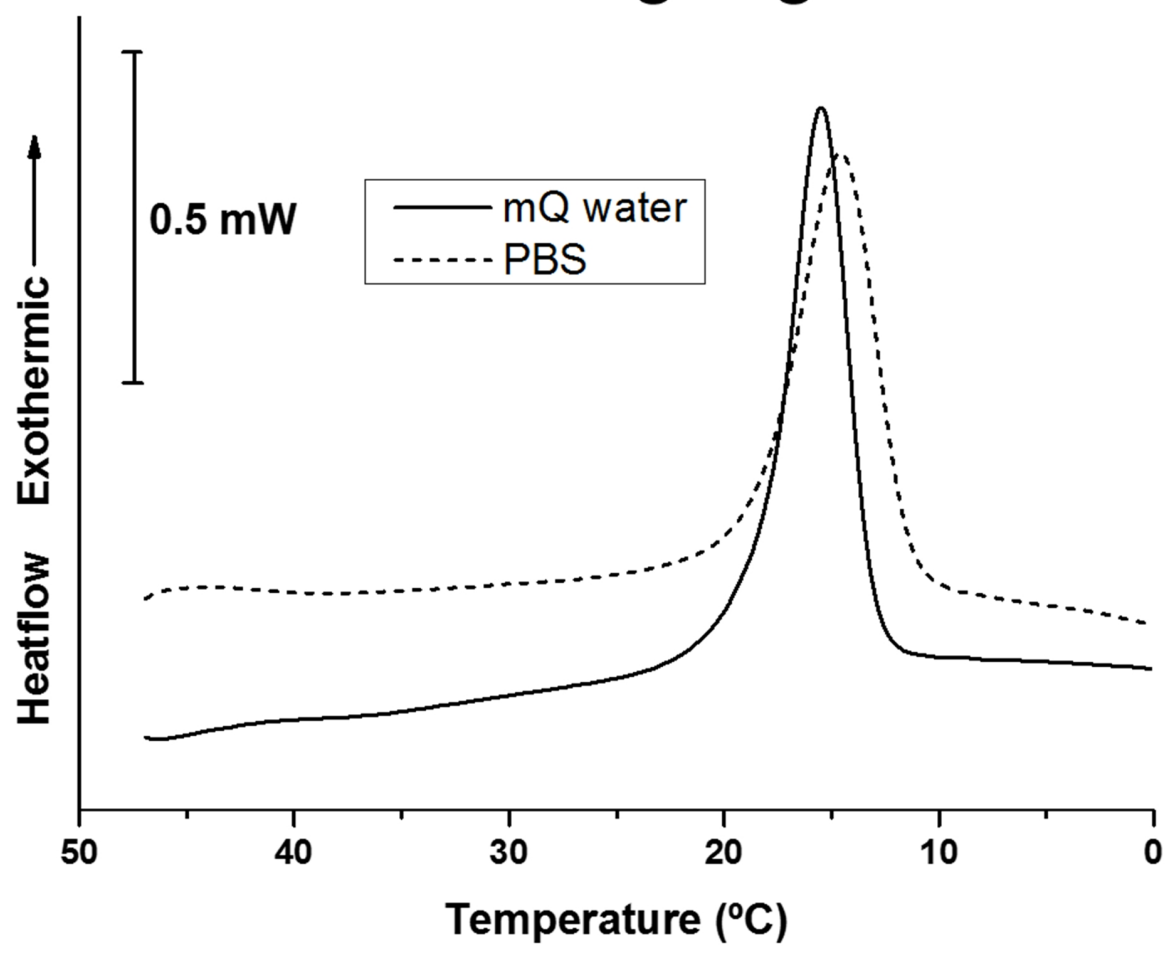




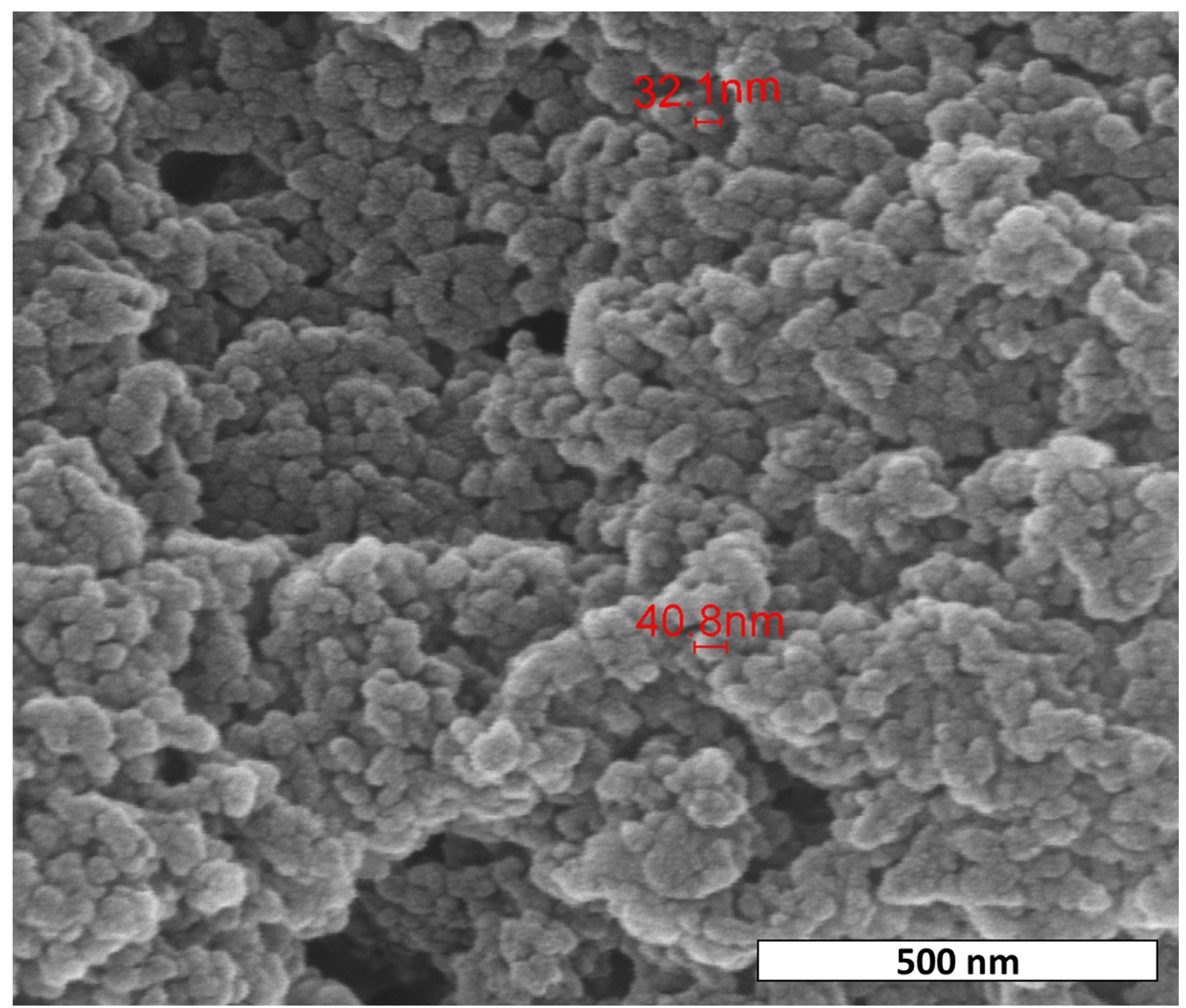


a

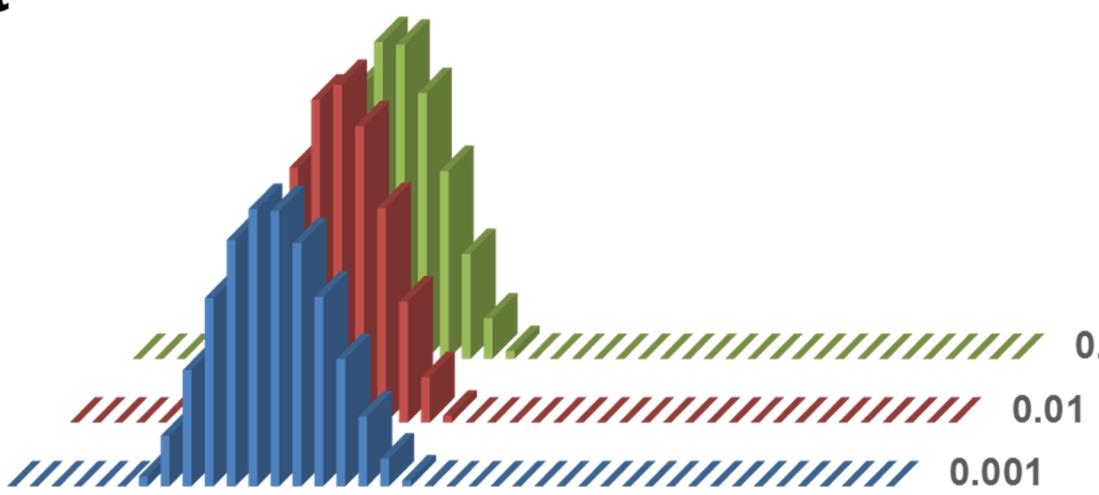

ఇ

Size $(\mathrm{nm})$

\begin{tabular}{c|c|c}
$\begin{array}{c}\text { Concentration } \\
(\mathrm{mg} / \mathrm{mL})\end{array}$ & $\begin{array}{c}\text { Z-average } \\
(\mathrm{nm})\end{array}$ & PDI \\
\hline $\mathbf{0 . 0 0 I}$ & $\mid 47.5( \pm 3.45 \mathrm{I})$ & $0.113( \pm 0.016)$ \\
$\mathbf{0 . 0 1}$ & $\mid 54.2( \pm 1.727)$ & $0.071( \pm 0.017)$ \\
$\mathbf{0 . 1}$ & $\mid 47.2( \pm 2.590)$ & $0.078( \pm 0.020)$
\end{tabular}

b

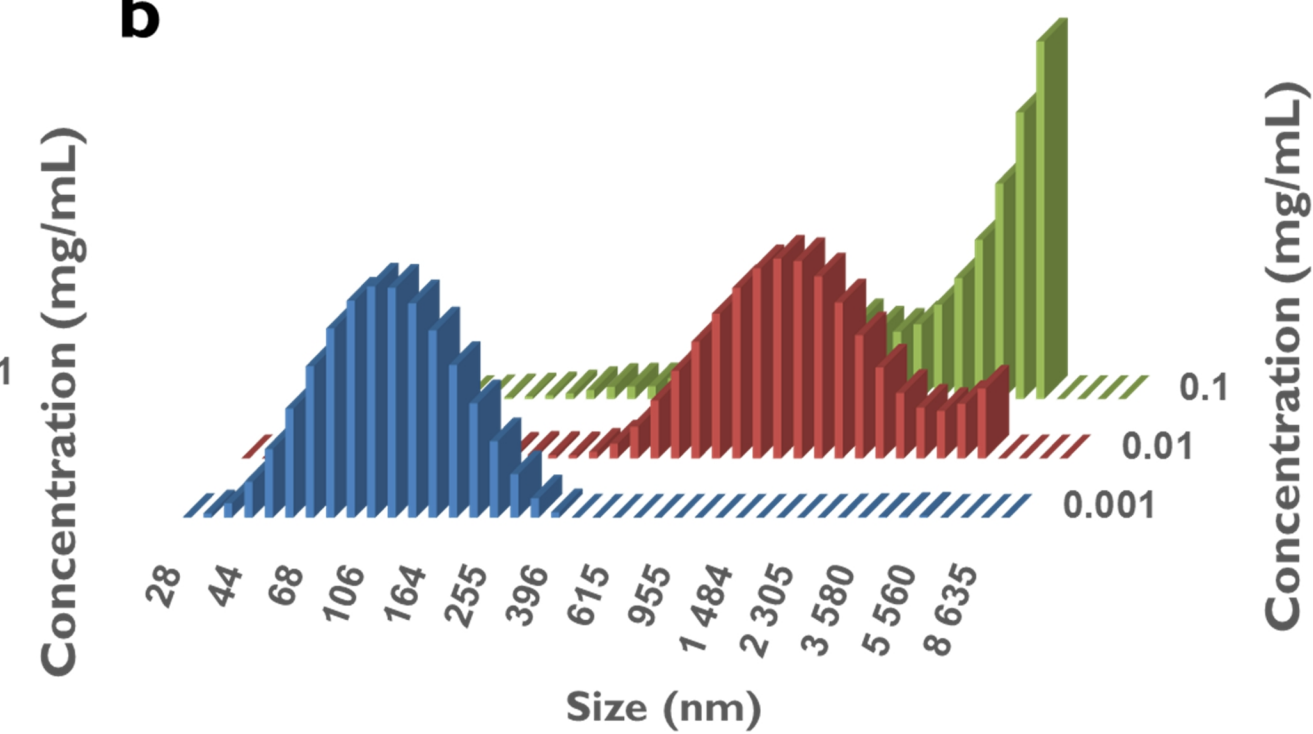

\begin{tabular}{c|c|c|}
$\begin{array}{c}\text { Concentration } \\
(\mathrm{mg} / \mathrm{mL})\end{array}$ & $\begin{array}{c}\text { Z-average } \\
(\mathrm{nm})\end{array}$ & PDI \\
\hline $\mathbf{0 . 0 0 1}$ & $108.5( \pm \mathrm{I} 4.95)$ & $0.170( \pm 0.018)$ \\
$\mathbf{0 . 0 1}$ & $674.3( \pm 160.1)$ & $0.354( \pm 0.074)$ \\
$\mathbf{0 . 1}$ & $1283( \pm 243.1)$ & $0.560( \pm 0.087)$
\end{tabular}


a

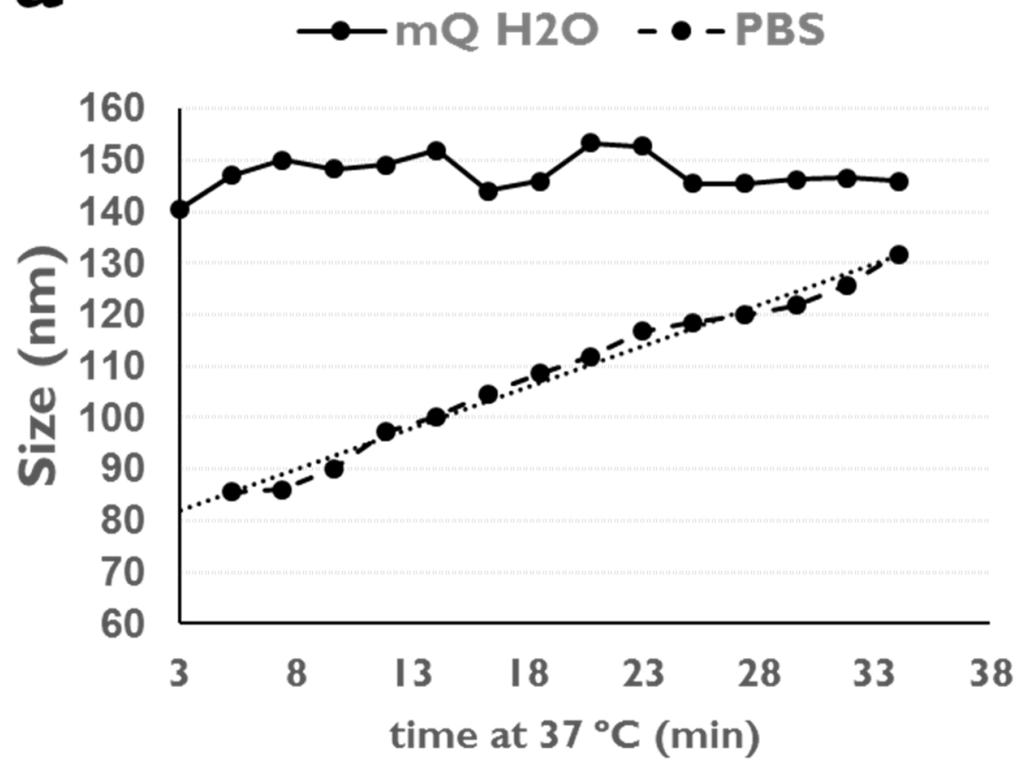

C

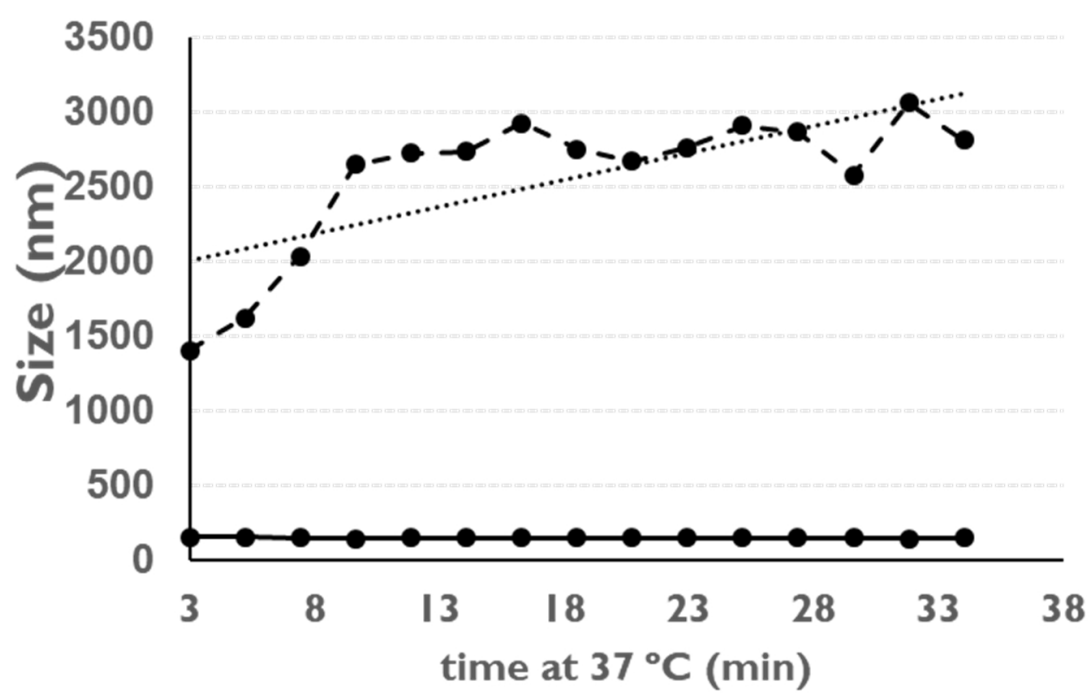

time at $37^{\circ} \mathrm{C}$ (min) b

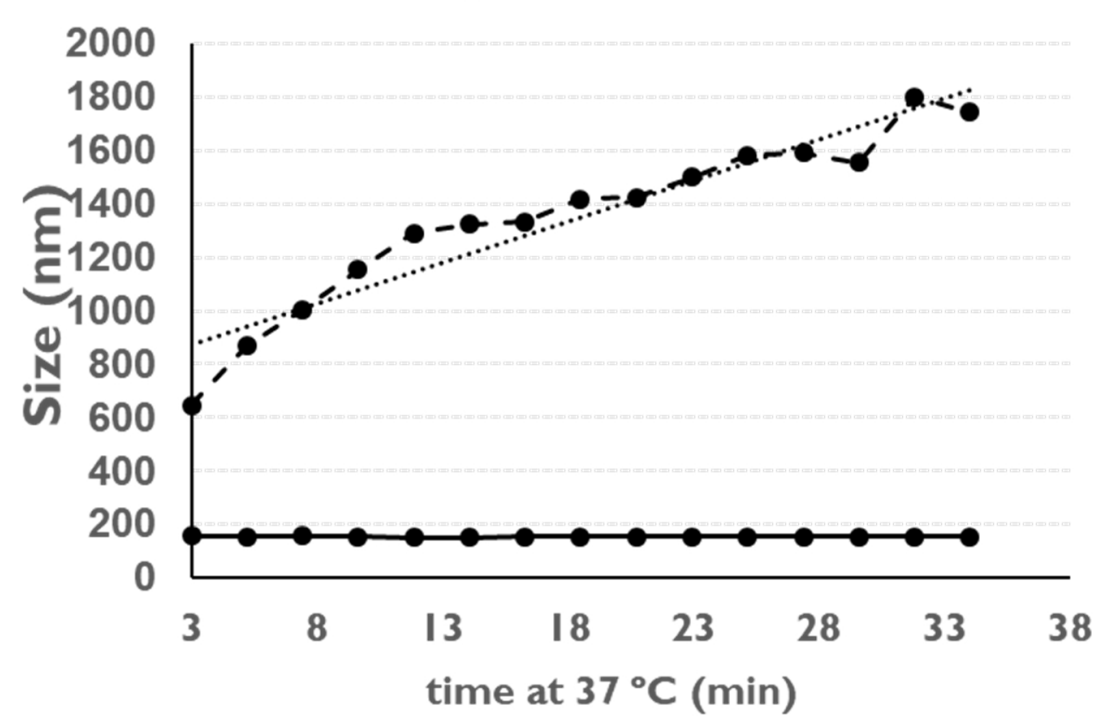

d

\begin{tabular}{cc|}
$\begin{array}{c}\text { Concentration of } \\
\text { Hep-A200 } \\
(\mathbf{m g} / \mathbf{m L})\end{array}$ & $\mathbf{r}^{2}$ of PBS sample \\
\hline 0.001 & 0.98 \\
\hline 0.01 & 0.90 \\
\hline 0.1 & 0.54 \\
\hline
\end{tabular}


a P. aeruginosa E. coli B. subtilis S. aureus

Negative control
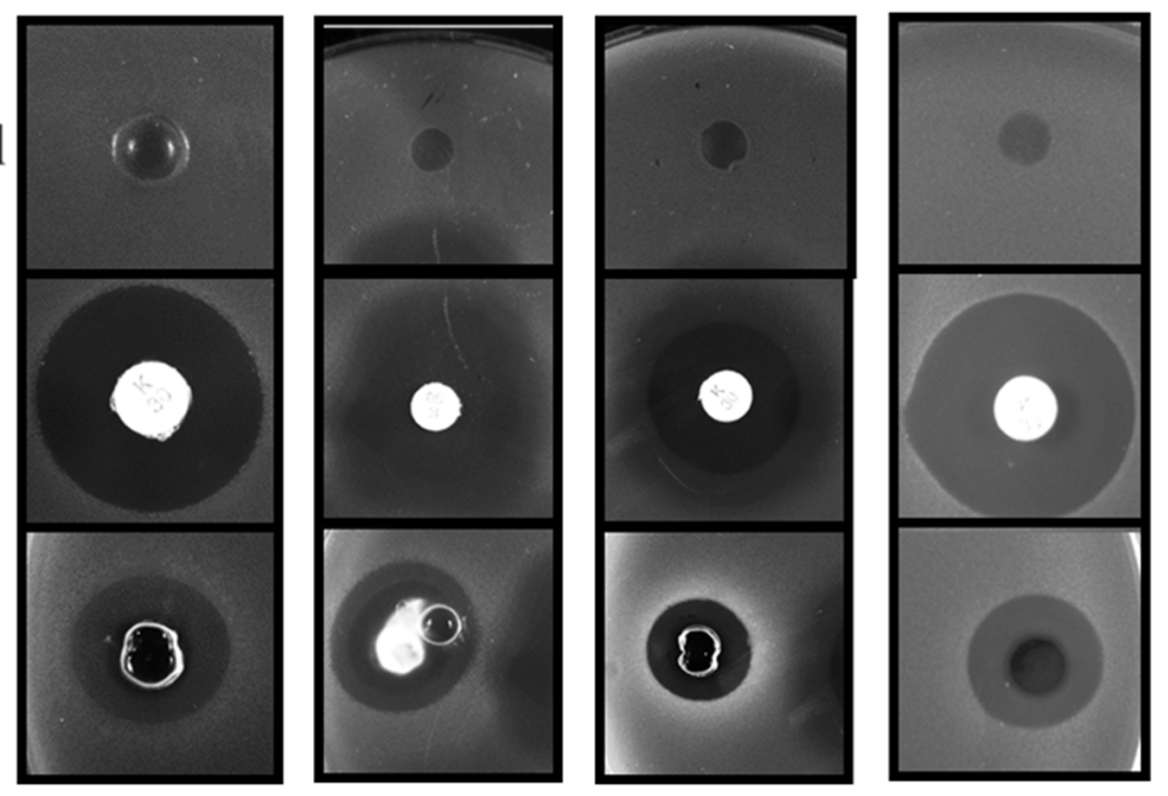

b

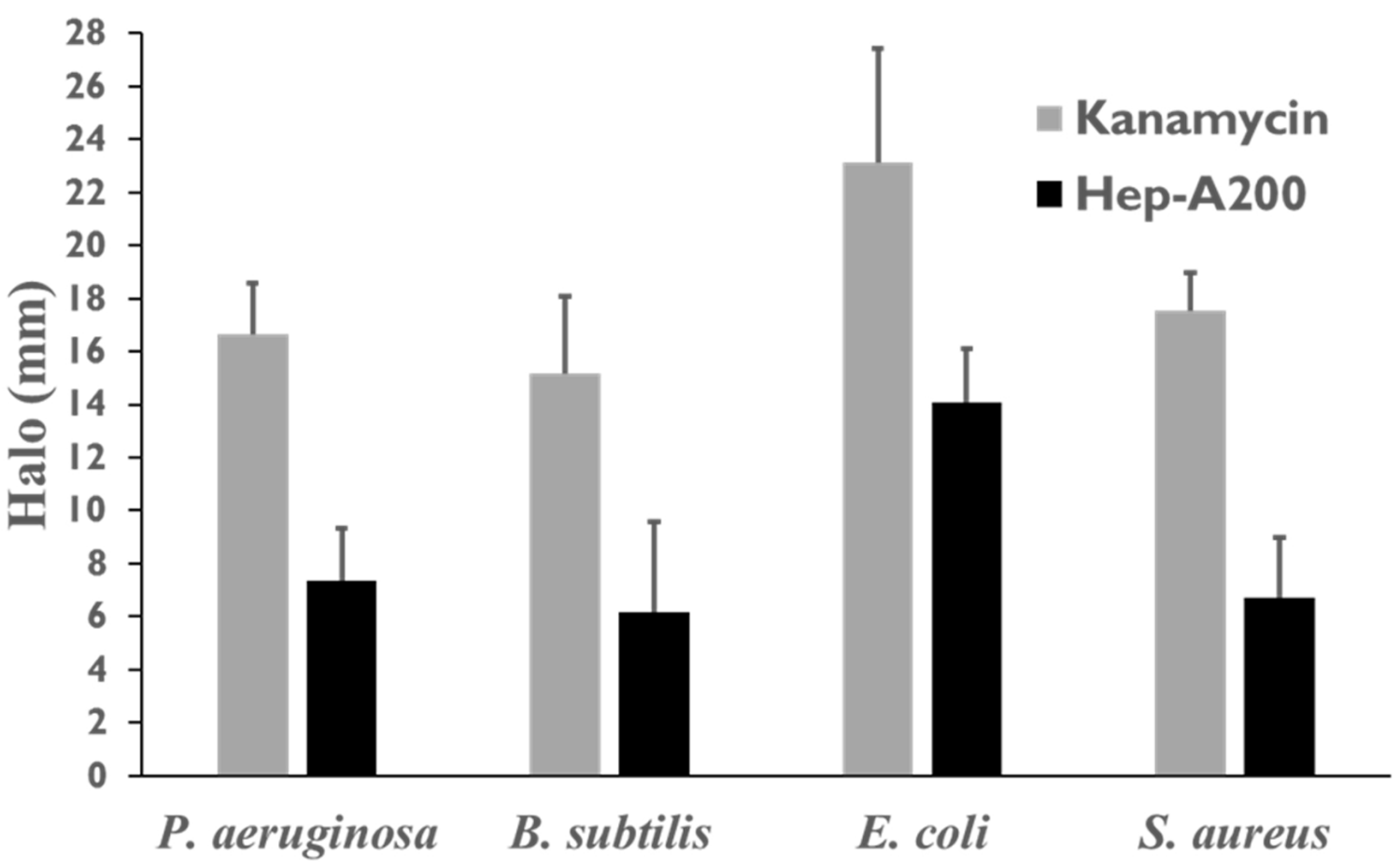




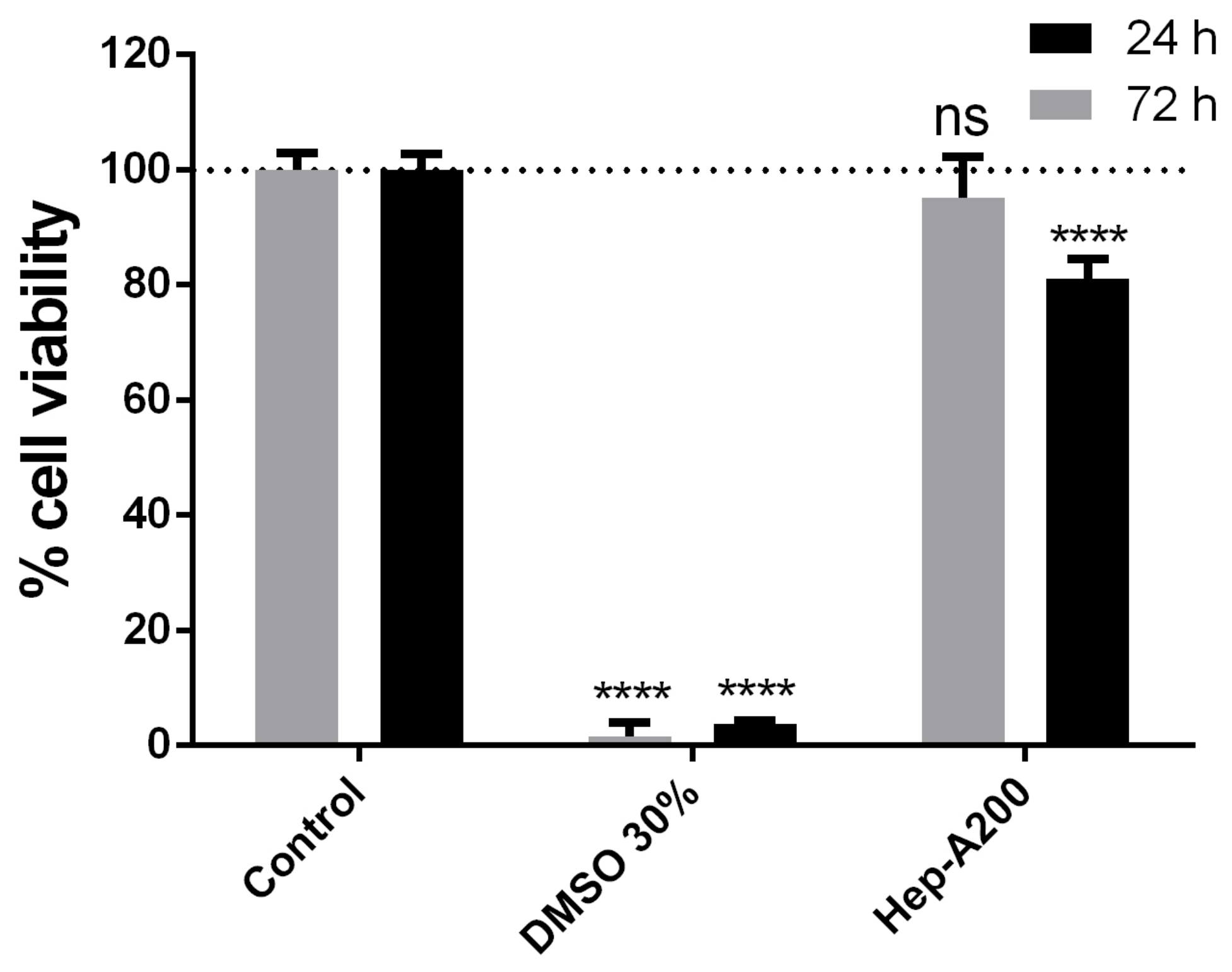




\section{Supplementary Information}

Production of bioactive Hepcidin by recombinant DNA tagging with an elastin-like recombinamer

A da Costa ${ }^{1 *}$, A M Pereira', A C Gomes ${ }^{1}$, J C Rodriguez-Cabello ${ }^{2,3}$, M Casal $^{1} \#$, R

Machado $^{1 * \#}$

${ }^{1}$ CBMA (Centre of Molecular and Environmental Biology), Department of Biology, University of Minho, Campus de Gualtar, 4710-057 Braga, Portugal

${ }^{2}$ Bioforge (Group for Advanced Materials and Nanobiotechnology), Edificio LUCIA, Universidad de Valladolid, Valladolid, Spain

${ }^{3}$ Networking Research Centre on Bioengineering, Biomaterials and Nanomedicine (CIBER-BBN), E-47011 Valladolid, Spain

\# - Both authors contributed equally and are listed in alphabetical order

* Corresponding authors:

Raul Machado: raulmachado@bio.uminho.pt; raulmachado@gmail.com

André Costa: andrecosta@bio.uminho.pt 
a

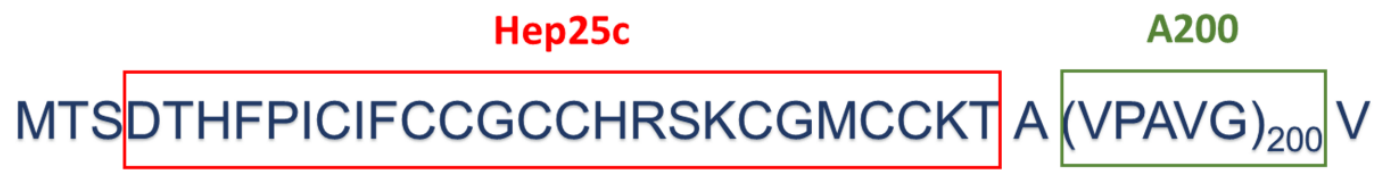

b

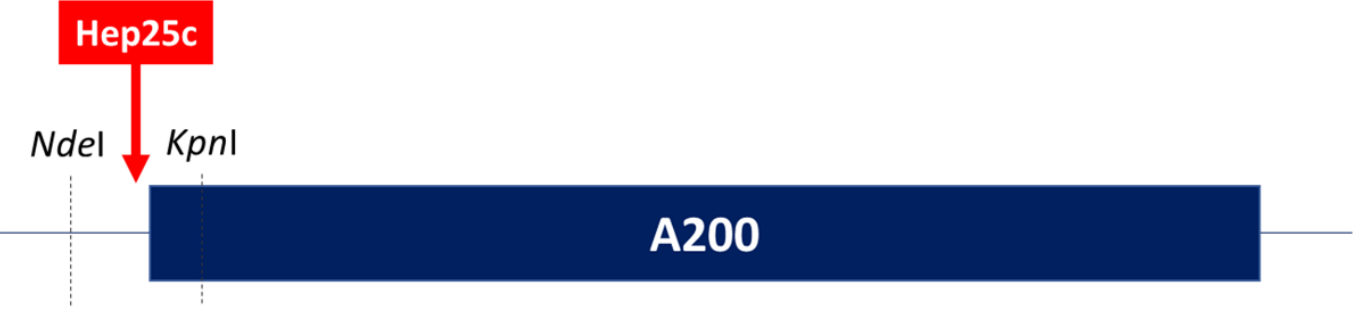

C

\begin{tabular}{cc}
\hline Protein & Theoretical molecular weight \\
\hline Hep25c & $2.80 \mathrm{KDa}$ \\
Hep-A200 & $88.0 \mathrm{KDa}$ \\
\hline
\end{tabular}

Supplementary figure 1 - Schematics of Hep-A200 construction. a) Amino acid sequence of Hep-A200; b) Schematics of the cloning strategy for the construction of Hep-A200 DNA coding sequence; c) Theoretical molecular weights of Hep25c and Hep-A200. 


\section{Thiol quantification}

Free thiol quantification was performed following the Ellman assay [1-3]. This assay exploits the rapid and stoichiometric reaction of the Ellman's reagent (5,5' -dithiobis(2nitrobenzoic acid), DTNB) that reacts with free sulfhydryl groups, yielding a mixed disulfide and the yellow colored 2-nitro-5-thiobenzoic acid (TNB) which can be spectrophotometrically determined by measuring the absorbance of the $\mathrm{TNB}^{2-}$ anion at $412 \mathrm{~nm}$. Briefly, quantification of thiol groups was assessed by means of a calibration curve performed with L-cysteine hydrochloride monohydrate (Merck) at concentrations of $1.50,1.25,1.00,0.75,0.50,0.25$ and $0.00 \mathrm{mM}$ in reaction buffer $(0.1 \mathrm{M}$ sodium phosphate, $1 \mathrm{mM}$ EDTA, pH 8.0). Ellman's reagent (4 mg of DTNB per mL of reaction buffer) was added followed by incubation at room temperature for 15 minutes. The absorbance of each sample was measured at $412 \mathrm{~nm}\left(\mathrm{~A}_{412}\right)$ and used to produce a standard curve $\left(\mathrm{R}^{2}=0.9977\right)$ (Supplementary figure 2$)$. Determination of free thiol groups in Hep-A200 was performed in $1 \%(\mathrm{w} / \mathrm{v})$ protein solutions in reaction buffer with DTNB. At the same time, a 1\% (w/v) Hep-A200 with $1 \mathrm{mM}$ of 1,4-dithiothreitol (DTT, Sigma-Aldrich) in reaction buffer with DTNB was also prepared. Addition of DTT was used for comparison purposes, to evaluate differences in the content of free sulfhydryl groups under reducing conditions. All measurements were performed with two independent experiments. The total concentration of free sulfhydryl groups was estimated by i) comparison to the standard curve, and ii) by applying equation 1 considering a value of $14,150 \mathrm{M}^{-1} \mathrm{~cm}^{-1}$ as the molar extinction coefficient of DTNB.

$A=\varepsilon \times l \times c$

where $A$ is the absorbance at $412 \mathrm{~nm}, \varepsilon$ is the molar absorptivity of DTNB $\left(\varepsilon_{420}=14,150\right.$ $\mathrm{M}^{-1} \mathrm{~cm}^{-1}, l$ is the path length in centimeters $(1 \mathrm{~cm})$ and $c$ is the molarity (moles/liter).

The average absorbance values and the estimated concentration of free sulfhydryl groups is represented in Supplementary table 1. Results demonstrate that native HepA200 (without DTT) presents a lower content of free sulfhydryl groups than the reduced counterpart (with DTT), indicating the formation of disulfide bridges. 


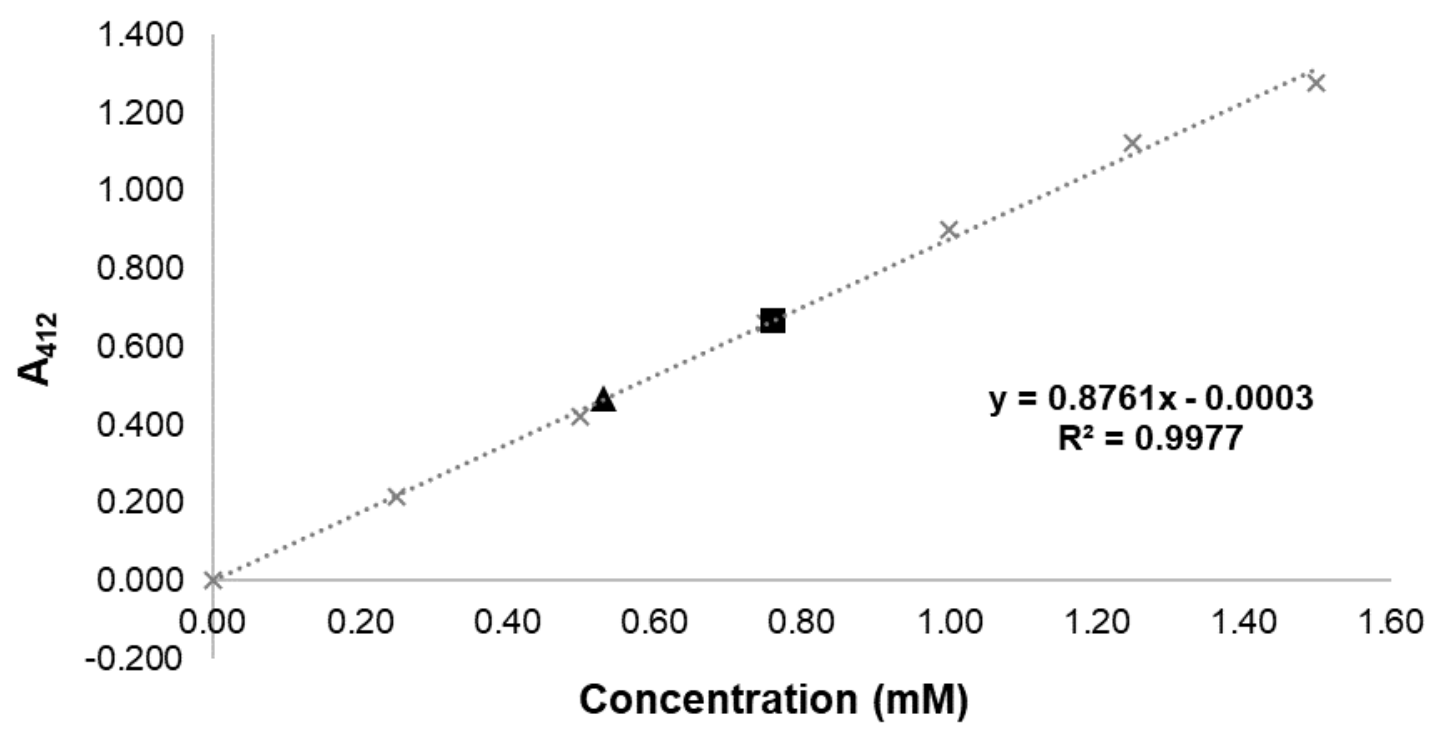

Supplementary figure 2 - Determination of free thiol groups in Hep-A200 by Ellman's assay. Quantification of 1\% (w/v) Hep-A200 ( $\Delta$ ) and 1\% (w/v) Hep-A200 + 1 mM DTT ( $\boldsymbol{\square}$ ) solutions was determined by comparison with a calibration curve performed with cysteine standards at 1.50, 1.25, 1.00, 0.75, 0.50, 0.25 and $0.00 \mathrm{mM}(\times)$.

Supplementary table 1 - Absorbance values and free sulfhydryl concentration obtained for $1 \%(\mathrm{w} / \mathrm{v})$ Hep-A200 with and without $1 \mathrm{mM}$ of DTT. Concentrations were estimated using the standards curve and by following the Beer-Lambert Law assuming an extinction coefficient of $14,150 \mathrm{M}^{-1} \mathrm{~cm}^{-1}$ for TNB.

\begin{tabular}{|c|c|c|c|}
\hline Sample & $\begin{array}{c}\text { Absorbance } \\
\left(\mathbf{A}_{\mathbf{4 1 2}}\right)\end{array}$ & $\begin{array}{c}\text { Concentration (mM) } \\
\text { estimated using } \\
\text { standard curve }\end{array}$ & $\begin{array}{c}\text { Concentration (mM) } \\
\text { estimated using } \\
\text { molar absorptivity }\end{array}$ \\
\hline $\begin{array}{c}1 \%(\mathrm{w} / \mathrm{v}) \mathrm{Hep}- \\
\mathrm{A} 200\end{array}$ & $0.466 \pm 0.007$ & 0.532 & 0.369 \\
\hline $\begin{array}{c}1 \%(\mathrm{w} / \mathrm{v}) \mathrm{Hep}- \\
\mathrm{A} 200+1 \mathrm{mM} \\
\mathrm{DTT}\end{array}$ & $0.666 \pm 0.017$ & 0.760 & 0.527 \\
\hline
\end{tabular}




\section{References:}

1. Aitken, A. and M. Learmonth, Estimation of disulfide bonds using Ellman's reagent, in The protein protocols handbook, 1996. Springer. p. 487-488.

2. Ellman, G.L., Tissue sulfhydryl groups. Archives of Biochemistry and Biophysics, 1959. 82(1): p. 70-77.

3. Winther, J.R. and C. Thorpe, Quantification of thiols and disulfides. Biochimica et Biophysica Acta (BBA) - General Subjects, 2014. 1840(2): p. 838-846. 